\title{
Comparison of hypoxemia, intubation procedure, and complications for non- invasive ventilation against high-flow nasal cannula oxygen therapy for patients with acute hypoxemic respiratory failure: a non- randomized retrospective analysis for effectiveness and safety (NIVaHIC-aHRF)
}

Chao Zhang(D) and Min Ou* (1)

\begin{abstract}
Background: Optimization of preoxygenation procedure can help to secure the method of intubation by reducing the risks of severe hypoxemia and other problems. There is confusion for efficacy of non-invasive ventilation compared to high-flow oxygen therapy regarding occurrence of severe hypoxemia during the intubation procedure. The purpose of the study was to compare the difference between noninvasive ventilation and high flow oxygen therapy to prevent desaturation during laryngoscopy.

Methods: Patients underwent high-flow nasal cannula oxygen therapy (HCO cohort, $n=161$ ) or non-invasive ventilation procedure (NIV cohort, $n=154$ ) for oxygenation and ventilation due to acute hypoxemic respiratory failure in the intensive care unit. Data before preoxygenation, preoxygenation, intubation, laryngoscopy, and complications of patients due to tracheal intubation were retrospectively collected and analyzed.

(Continued on next page)
\end{abstract}

\footnotetext{
* Correspondence: min.quh6@gmail.com

The Sixth Department of Health Care, The Second Medical Center \& National Clinical Research Center for Geriatric Diseases, Chinese PLA General Hospital, Beijing 100048, China
}

(c) The Author(s). 2021, corrected publication April 2021. Open Access This article is licensed under a Creative Commons Attribution 4.0 International License, which permits use, sharing, adaptation, distribution and reproduction in any medium or format, as long as you give appropriate credit to the original author(s) and the source, provide a link to the Creative Commons licence, and indicate if changes were made. The images or other third party material in this article are included in the article's Creative Commons licence, unless indicated otherwise in a credit line to the material. If material is not included in the article's Creative Commons licence and your intended use is not permitted by statutory regulation or exceeds the permitted use, you will need to obtain permission directly from the copyright holder. To view a copy of this licence, visit http://creativecommons.org/licenses/by/4.0/. The Creative Commons Public Domain Dedication waiver (http:// creativecommons.org/publicdomain/zero/1.0/) applies to the data made available in this article, unless otherwise stated in a credit line to the data. 


\begin{abstract}
(Continued from previous page)
Results: There was no difference between both cohorts for the demographical and clinical conditions of the patients before preoxygenation ( $p>0.05$ for all parameters), numbers of patients with severe hypoxia during the intubation procedure (35 vs. $45, p=0.303$ ), the time duration of laryngoscopy $(p=0.847$ ), number of laryngoscopies attempts $(p=0.804)$, and immediate and late complications during the intubation procedure. The values of pulse oximetry were reported higher for patients of NIV cohort than those of HCO cohort during preoxygenation. Fewer numbers of patients were reported with severe hypoxia among patients of the NIV cohort than those of the HCO cohort (24 vs., 40, $p=0.042$ ) who have moderate-to-severe hypoxemia (partial pressure of arterial oxygen to fraction of inspired oxygen ratio $\leq 200 \mathrm{mmHg}$ ) before preoxygenation. The most common complications were hypertension, pulmonary aspiration, and increased 30-day mortality.

Conclusions: When compared, there was no difference between non-invasive ventilation technique and high-flow oxygen therapy to minimize severe hypoxia prior to laryngoscopy and endotracheal intubation in patients with acute respiratory failure.
\end{abstract}

Keywords: High-flow oxygen therapy, Hypoxia, Laryngoscopy, Intubation, Non-invasive ventilation, Preoxygenation

\section{Background}

Tracheal intubation is commonly used in intensive care units [1]. The tracheal intubation procedure is safe and complications are rare in clinical practice but are fatal. It has a complications like severe hypoxemia, cardiac or neurological ischemia, and cardiovascular collapse especially in the intensive care units [2]. Among patients admitted in the intensive care units, the severe hypoxemia may occur in $20-25 \%$ of patients [3] and cardiac arrest may occur in $2-3 \%$ of patients [4] and most of them are intubated for acute respiratory failure purpose. Optimization of the preoxygenation procedure can help to secure the method of intubation by reducing the risks of severe hypoxemia and other problems [2].

Oxygenation devices used mostly in the intensive care units are non-invasive ventilation (NIV) and high-flow nasal cannula oxygen therapy (high-flow oxygen; HCO) and that can provide a higher fraction of inspired oxygen than standard oxygen through the Bag Valve Mask [5, 6]. $\mathrm{HCO}$ is able to deliver constant high gas flow through nasal prongs up to $70 \mathrm{~L} / \mathrm{min}$, resulting in a high $(>0.9)$ fraction of inspired oxygen, which is similar to that of the reservoir Bag Valve Mask [7]. During the apneic phase of intubation after anesthetic induction, $\mathrm{HCO}$ can maintain oxygenation and avoid hypoxemia. However, NIV is removed during the apneic phase of intubation after anesthetic induction [2]. A prospective study [8] and a randomized trial [9] are reported that during intubation, compared with the reservoir Bag Valve Mask for oxygenation and ventilation, $\mathrm{HCO}$ is able to decrease the incidences of severe hypoxemia during intubation procedure. While the randomized controlled trials [1012] are not provided satisfactory results for $\mathrm{HCO}$ compared to the Bag Valve Mask for preoxygenation. However, a randomized trial on acute hypoxemic respiratory failure patients [2] is reported that NIV and HCO both are equally effective. Therefore, there is confusion for efficacy of NIV compared to HCO regarding occurrence of severe hypoxemia during the intubation procedure.

The objective of the non-randomized retrospective study was to compare NIV against HCO regarding occurrences of hypoxemia, intubation procedure, and laryngoscopy procedure in patients undergoing tracheal intubation due to acute hypoxemic respiratory failure admitted into the intensive care units.

\section{Methods \\ Study population}

Patients (> 18 years age) undergoing tracheal intubation (under NIV or HCO) due to acute hypoxemic respiratory failure (signs of respiratory distress) into the intensive care units were included in the analysis. Patients less than 18 years in age, patients who were admitted to the operating room and underwent tracheal intubation, and patients who had a Glasgow coma score $<8$ were excluded from the analysis.

\section{Non-invasive ventilation procedure}

Here preoxygenation was performed through a face mask connected to the intensive care unit ventilator by Bi-level Positive Airway Pressure machine (GE Healthcare, Chicago, IL, USA). The pressure-support of ventilation was adjusted to get a $6-8 \mathrm{~mL} / \mathrm{kg}$ expired tidal volume, $10 \mathrm{~cm} \mathrm{H}_{2} \mathrm{O}$ positive end-expiratory pressure, and 1.0 fraction of inspired oxygen. NIV procedure was continued to provide oxygenation and ventilation during preoxygenation and between induction and laryngoscopy. NIV procedure did not continue to provide oxygenation and ventilation during laryngoscopy.

\section{High-flow nasal cannula oxygen therapy}

Preoxygenation was performed by oxygen continuously through nasal prongs, with a $60 \mathrm{~L} / \mathrm{min}$ gas flow by a heated humidifier (Apex Medical Corporation, Taipei, 
Taiwan) and 1.0 fraction of inspired oxygen. The emergency physician(s) was performed a jaw thrust to maintain an upper airway of the patient and high-flow oxygen therapy was continued during laryngoscopy until the endotracheal tube was inserted into the trachea. This therapy was continued to provide oxygenation and little ventilation during preoxygenation, between induction and laryngoscopy, and during laryngoscopy.

\section{Preoxygenation}

Preoxygenation was done in a semi-recumbent position of patients at $30^{\circ} \mathrm{C}$ for $3-5 \mathrm{~min}$. Intubation care bundle management was included the pre-intubation presence of two operators, systematic fluid loading $(500 \mathrm{~mL}$ normal saline (Baxter pharmaceuticals, Deerfield, Illinois, USA)) using $0.2-0.3 \mathrm{mg} / \mathrm{kg}$ etomidate (EtomidateLipuro, B. Braun Melsungen AG, Melsungen, Germany) or $1.5-3 \mathrm{mg} / \mathrm{kg}$ ketamine (Ketalar ${ }^{\oplus}$, Par Pharmaceutical Chestnut Ridge, NY, USA), combined with $0.6-1 \mathrm{mg} / \mathrm{kg}$ rocuronium (Fresenius-Kabi Inc., Lake Zurich, IL, USA) or $1 \mathrm{mg} / \mathrm{kg}$ succinylcholine (Anectine ${ }^{\circ}$, Sandoz, SanofiAventis, Princeton, NJ, USA) [3]. If intubation was not successful then video laryngoscopy was adopted. If video laryngoscopy was not successful then surgical tracheostomy (using Tracheostomy tube, F. Hoffmann-La Roche AG, Basel, Switzerland) was adopted. After endotracheal intubation, patients were mechanically ventilated (CARA $\mathrm{T}$ II PRO, Hoffrichter GmbH, Mettenheimerstraße, Schwerin, Germany) at 6-8 mL/ kg tidal volume, 25-30 breaths/ min respiratory rate, $5 \mathrm{~cm} \mathrm{H}_{2} \mathrm{O}$ positive endexpiratory pressure, and 1.0 fraction of inspired oxygen to maintain $90 \%$ or above pulse oximetry (Masimo, Irvine, CA, USA). The partial pressure of arterial oxygen to fraction of inspired oxygen ratio was calculated as per Eq. (1) [2].

$$
\begin{aligned}
& \text { Fraction of inspired oxygen } \\
& \quad=0.21+\text { oxygen flow rate } \times 0.03
\end{aligned}
$$

\section{Cohorts}

Patients who had recent laryngeal, esophageal, or/ and substantial facial fractures underwent $\mathrm{HCO}$ therapy (HCO cohort) otherwise all patients underwent NIV technique (NIV cohort) for acute hypoxemic respiratory failure in the intensive care unit.

\section{Simplified acute physiology score II}

It was calculated from 17 variants before preoxygenation from the information about medical history. Scores are ranged from 0 to 163 , with higher the scores a more severe diseased condition [13].

\section{Modified Cormack-Lehane grade}

Modified Cormack-Lehane grade was evaluated in the range from I to IV. If the vocal cords were fully viewed then it was graded as I. If the vocal cords were partially viewed then it was graded as IIA. If only arytenoids and epiglottis seen then it was graded as IIB. If the part of the glottis could not be visualized but the epiglottis could be visualized then it was graded as III. If neither glottis nor epiglottis could be visualized then it was graded as IV [14].

\section{Intubation difficulty scale score}

Intubation Difficulty Scale score was defined as 0-2: easy intubation, 3-4: slight difficult intubation, and 5 or more as moderate or major difficulties in intubation [15].

\section{MACOCHA score}

It was calculated from seven variants (Mallampati score III or IV, apnea syndrome, cervical spine limitation, opening mouth $<3 \mathrm{~cm}$, coma, hypoxia, and non-trained anesthesiologists). Scores are ranged from 0 to 12, with higher the scores a higher the risk of difficult intubation [16].

\section{Hypoxemia}

A decrease in pulse oximetry reading below $80 \%$ for at least $5 \mathrm{~s}$ during intubation procedure was considered as severe hypoxia [2]. The lowest value of pulse oximetry value during the intubation procedure, the value of pulse oximetry reading at the beginning of preoxygenation, and the reading of pulse oximetry value at the end of preoxygenation were collected.

\section{Laryngoscopy}

Attempts to insert the endotracheal tube (F. HoffmannLa Roche AG, Basel, Switzerland) into the trachea lasting $10 \mathrm{~min}$ or more time using conventional laryngoscopy, duration of laryngoscopy, and the number of laryngoscopy attempt(s) were recorded.

\section{Complications}

Data regarding use of alternative management devices, agitation, immediate complications (arterial hypotension, bradycardia, sustained arrhythmia, esophageal intubation, regurgitation, gastric distension, injuries in the oral cavity, new infiltrate on chest radiograph, cardiac arrest, and death), and late complications (worsening of SOFA (Sepsis-related Organ Failure Assessment; score from days 1 to 7 . Scores of SOFA are ranged from 0 to 24 , with higher the scores a more severe organ failure [17]), the occurrence of ventilator-associated pneumonia, duration of mechanical ventilation, and length of stay in the intensive care unit) were collected from medical records of institute. 
The preoxygenation, intubation, and laryngoscopy were performed by emergency physicians of institute. Also, Outcomes were measured by emergency physicians of institute.

\section{Statistical analysis}

The study was performed with the hypothesis that severe hypoxia could have occurred in $25 \%$ of patients during the preoxygenation procedure $[11,12]$. The study was enrolled in 315 patients with $80 \%$ power $(\beta=0.2)$ and $5 \%$ two-sided type-I error $(\alpha=0.05)$ at a $95 \%$ level of confidence and the sample size (minimum patients required in each cohort) was reported 151. SPSS v25.0, IBM Corporation, Armonk, NY, USA was used for statistical analysis purposes. Constant variables are reported as frequency (percentages) and continuous and ordinal variables are demonstrated as mean \pm standard deviation (SD). The Fischer exact test was performed for constant variables and the Mann-Whitney $U$-test [2] was performed for continuous and ordinal variables at a two sided $\alpha$-level of 0.05 . All outcomes were considered exploratory. All results were considered significant at a 95\% confidence level.

\section{Results}

\section{Study population}

From 15 January 2018 to 1 October 2019, a total of 493 patients underwent tracheal intubation at the Chinese PLA General Hospital, Beijing, China and the referring hospitals. Among them, seven patients were below 18 years of age, 165 patients underwent tracheal intubation at the operating room, six patients had a Glasgow coma score $<8$. Therefore, data of these patients $(n=178)$ were excluded from the analysis. Data of the demographical and clinical conditions before preoxygenation, preoxygenation, intubation procedure, laryngoscopy procedure, and complications during intubation procedure of 315 patients ( $>18$ years age) undergoing tracheal intubation due to acute hypoxemic respiratory failure admitted to the intensive care units were included in the analysis (Fig. 1). A total of 161 patients had recent laryngeal, esophageal, or/ and substantial facial fractures. Therefore, these patients underwent $\mathrm{HCO}$ therapy ( $\mathrm{HCO}$ cohort) and 154 patients underwent NIV procedure (NIV cohort) for oxygenation and ventilation.

\section{Demographical and clinical conditions}

All enrolled patients had a partial pressure of arterial oxygen to fraction of inspired oxygen ratio less than 300 $\mathrm{mmHg}$ and respiratory rates more than 25 breaths/ min. There were no significant differences in the demographical and clinical conditions of the patients before preoxygenation between both cohorts $(p>0.05$ for all parameters, Table 1). All patients underwent preoxygenation strategies in intensive care units.

\section{Hypoxia}

A total of $35(23 \%)$ patients of the NIV cohort had severe hypoxia and $44(28 \%)$ patients of the $\mathrm{HCO}$ cohort had severe hypoxia $(p=0.303$, Table 2$)$ during the

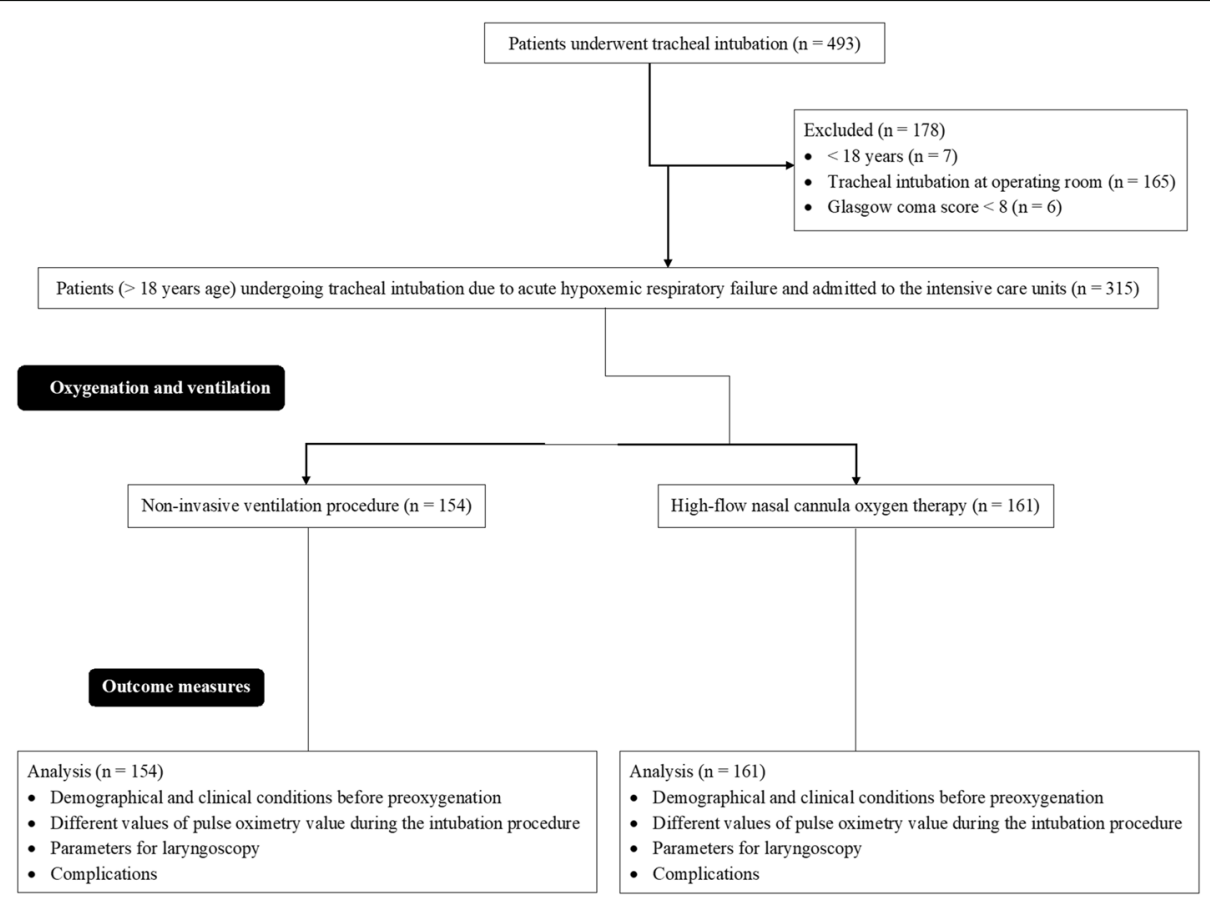

Fig. 1 Flow diagram of the oxygenation and ventilation 
Table 1 Demographical and clinical conditions of the patients before preoxygenation

\begin{tabular}{|c|c|c|c|}
\hline \multirow[t]{2}{*}{ Parameters } & \multicolumn{2}{|l|}{ Cohorts } & \multirow{2}{*}{$\begin{array}{l}\text { Comparisons } \\
\text { between } \\
\text { cohorts }\end{array}$} \\
\hline & NIV & $\mathrm{HCO}$ & \\
\hline Procedure for oxygenation and ventilation & Non-invasive ventilation & High-flow nasal cannula oxygen & \\
\hline Patients included in the analysis & 154 & 161 & $p$-value \\
\hline \multicolumn{4}{|l|}{ Age (years) } \\
\hline Minimum & 28 & 27 & \multirow[t]{3}{*}{0.377} \\
\hline Maximum & 68 & 67 & \\
\hline Mean \pm SD & $57.12 \pm 11.14$ & $58.22 \pm 10.91$ & \\
\hline \multicolumn{4}{|l|}{ Sex } \\
\hline Male & $105(68)$ & $107(66)$ & \multirow[t]{2}{*}{0.811} \\
\hline Female & $49(32)$ & $54(34)$ & \\
\hline Body-mass index $\left(\mathrm{kg} / \mathrm{m}^{2}\right)$ & $25.52 \pm 1.11$ & $25.22 \pm 1.85$ & 0.084 \\
\hline Simplified Acute Physiology Score II & $53 \pm 13$ & $50 \pm 15$ & 0.059 \\
\hline Sepsis-related Organ Failure Assessment score & $8.12 \pm 4.35$ & $9.01 \pm 4.61$ & 0.079 \\
\hline Underlying chronic lung disease & $42(27)$ & $51(32)$ & 0.459 \\
\hline Upper airway tract cancer history & $6(4)$ & $4(2)$ & 0.531 \\
\hline \multicolumn{4}{|l|}{ Reason for the intensive care unit admission } \\
\hline Respiratory infection & $54(35)$ & $61(38)$ & \multirow[t]{7}{*}{0.392} \\
\hline Chronic obstructive pulmonary disease exacerbation & $10(7)$ & $11(7)$ & \\
\hline Extra-pulmonary acute respiratory distress syndrome. & $15(10)$ & $12(7)$ & \\
\hline Pulmonary atelectasis & $5(3)$ & $3(2)$ & \\
\hline Shock & $42(27)$ & $57(35)$ & \\
\hline Cardiogenic pulmonary edema & $15(10)$ & $8(5)$ & \\
\hline Neurologic conditions & $13(8)$ & $9(6)$ & \\
\hline Vasopressor support at inclusion & $28(18)$ & $31(19)$ & 0.885 \\
\hline Bilateral pulmonary infiltrates & $77(50)$ & $82(51)$ & 0.911 \\
\hline Respiratory rates (breaths/ min) & $61 \pm 9$ & $62 \pm 8$ & 0.298 \\
\hline \multicolumn{4}{|c|}{ The partial pressure of arterial oxygen to fraction of inspired oxygen ratio } \\
\hline Mild hypoxemia (201-300 mmHg) & $34(22)$ & $35(22)$ & \multirow[t]{2}{*}{0.889} \\
\hline Moderate-to-severe hypoxemia ( $\leq 200 \mathrm{mmHg}$ ) & $120(78)$ & $126(78)$ & \\
\hline
\end{tabular}

Constant variables are reported as frequency (percentages) and continuous and ordinal variables are reported as mean \pm standard deviation (SD) For constant variables the Fischer exact test and for continuous and ordinal variables the Mann-Whitney U-test was performed for statistical analysis A $p$-value of less than 0.05 was considered significant

Fraction of inspired oxygen $=0.21+$ oxygen flow rate $\times 0.03$

Table 2 The different values of pulse oximetry value during the intubation procedure

\begin{tabular}{|c|c|c|c|}
\hline \multirow[t]{2}{*}{ Values of pulse oximetry } & \multicolumn{2}{|l|}{ Cohorts } & \multirow{3}{*}{$\begin{array}{l}\text { Comparisons } \\
\text { between } \\
\text { cohorts }\end{array}$} \\
\hline & NIV & $\mathrm{HCO}$ & \\
\hline Procedure for oxygenation and ventilation & $\begin{array}{l}\text { Non-invasive } \\
\text { ventilation }\end{array}$ & $\begin{array}{l}\text { High-flow nasal cannula } \\
\text { oxygen }\end{array}$ & \\
\hline Patients included in the analysis & 154 & 161 & $p$-value \\
\hline \multicolumn{4}{|l|}{ Hypoxemia } \\
\hline At the beginning of preoxygenation (mean \pm standard deviation) & $95 \pm 4 \%$ & $94 \pm 5 \%$ & 0.052 \\
\hline $\begin{array}{l}\text { The lowest value during the intubation procedure (mean } \pm \text { standard } \\
\text { deviation) }\end{array}$ & $78 \pm 4 \%$ & $77 \pm 6 \%$ & 0.084 \\
\hline Numbers of patients with severe hypoxia (frequency (percentages)) & $35(23)$ & $45(28)$ & 0.303 \\
\hline At the end of preoxygenation (mean \pm standard deviation) & $97 \pm 5 \%$ & $96 \pm 5 \%$ & 0.077 \\
\hline
\end{tabular}

For constant variables the Fischer exact test and for continuous and ordinal variables the Mann-Whitney $U$-test was performed for statistical analysis ${ }^{\mathrm{a}} \mathrm{A}$ decrease in pulse oximetry reading below $80 \%$ for at least $5 \mathrm{~s}$ during intubation procedure

A $p$-value of less than 0.05 was considered significant 
intubation procedure. The values of pulse oximetry were reported higher for patients of NIV cohort than those of HCO cohort (Table 3). Severe hypoxia had occurred among $11(32 \%)$ patients of the NIV cohort and 5 (14\%) patients of the $\mathrm{HCO}$ cohort $(p=0.093)$ who have mild hypoxemia (partial pressure of arterial oxygen to fraction of inspired oxygen ratio $=201-300 \mathrm{mmHg}$ ) before preoxygenation. Severe hypoxia had occurred among 24 (20\%) patients of the NIV cohort and 40 (32\%) patients of the HCO cohort $(p=0.042)$ who have moderate-tosevere hypoxemia (partial pressure of arterial oxygen to fraction of inspired oxygen ratio $\leq 200 \mathrm{mmHg}$ ) before preoxygenation (Fig. 2).

\section{Laryngoscopy}

There were no significant differences for the time duration of laryngoscopy $(p=0.847)$ and the number of laryngoscopies attempts $(p=0.804)$ between both cohorts (Table 4).

\section{Intubation scoring items}

There were no significant differences for MACOCHA score, Modified Cormack-Lehane grade, and Intubation Difficulty Scale score between both cohorts (Table 5).

\section{Immediate and late complications}

The most common complications were hypertension, pulmonary aspiration, and increased 30-day mortality. There was no significant difference for immediate complications (Table 6) and late complications (Table 7) between both cohorts during intubation procedure $(p>$ 0.05 for all).

\section{Discussion}

The study reported that NIV could not change the risk of severe hypoxia and complications during intubation procedure as compared to $\mathrm{HCO}$. The results of the severe hypoxia and complications of the current study were parallel with those of randomized trials $[2,12]$. Different oxygenation devices have no different effects on severe hypoxia and other complications during preoxygenation.

The study reported that NIV was reduced the risk of severe hypoxia as compared to HCO among patients with moderate-to-severe hypoxemia [18] before preoxygenation. The results of the risk of severe hypoxia among patients with moderate-to-severe hypoxemia before preoxygenation of the current study were agreed with those of a randomized trial [2]. NIV has beneficial effects on patients with the moderate-to-severe hypoxemic condition before preoxygenation during oxygenation and ventilation.

The current study is reported 25\% (80 out of 315) patients with severe hypoxia during preoxygenation. The results of the total numbers of patients reported with severe hypoxia of the current study were consistent with those of randomized trials [2, 10-12] but not consistent with the prospective, controlled study [3]. Accurate analysis of pulse oximetry value is required to record severe hypoxia conditions during preoxygenation. Also, the intubation procedure is performed in an emergency condition. Therefore, it is difficult to detect severe hypoxia conditions during preoxygenation.

At the end of preoxygenation, overall as well as individually for patients with mild hypoxemia and patients with moderate-to-severe hypoxemia [18] the values of pulse oximetry were reported higher for who underwent

Table 3 The different values of pulse oximetry value of patients according to different hypoxemia conditions during the intubation procedure

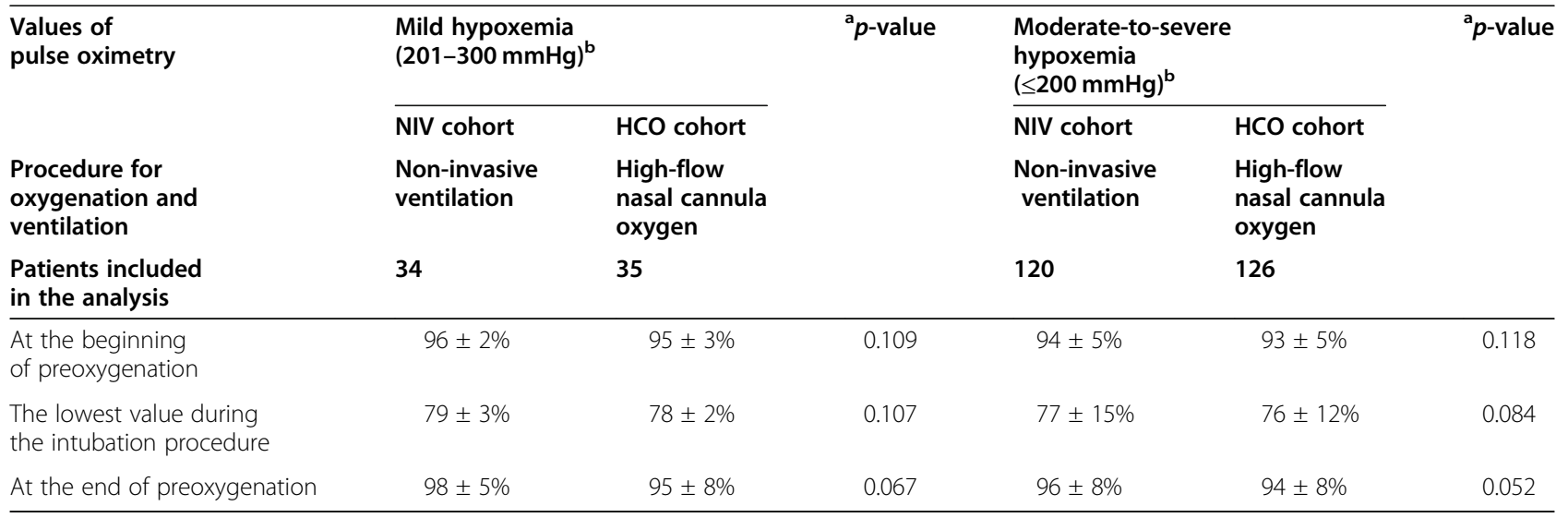

Variables are reported as mean \pm standard deviation (SD)

The Mann-Whitney $U$-test was performed for statistical analysis

${ }^{a}$ Comparisons between cohorts

${ }^{b}$ Partial pressure of arterial oxygen to fraction of inspired oxygen ratio

A $p$-value of less than 0.05 was considered significant 
$\square$ Patients with mild hypoxemia (partial pressure of arterial oxygen to fraction of inspired oxygen ratio $=201-300 \mathrm{mmHg}$ ) before preoxygenation ๑atients with moderate-to-severe hypoxemia (partial pressure of arterial oxygen to fraction of inspired oxygen ratio $\leq 200 \mathrm{mmHg}$ ) before preoxygenation

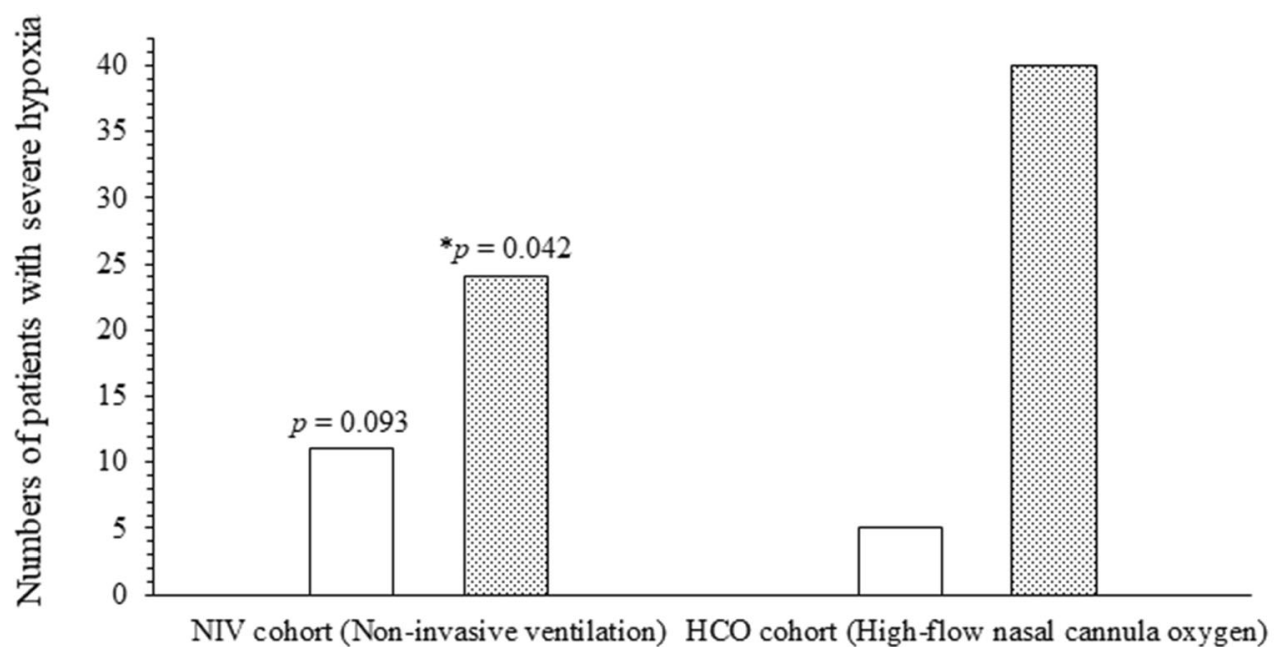

Fig. 2 The occurrence of severe hypoxia. Variables are reported as frequency. The Fischer exact test was performed for statistical analysis. A $p$ value of less than 0.05 was considered significant. ${ }^{*}$ Significantly lower than the HCO cohort. Severe hypoxia: A pulse oximetry value < $80 \%$ for at least 5 s during intubation procedure. Fraction of inspired oxygen $=0.21+$ oxygen flow rate $\times 0.03$

NIV than those underwent HCO. The results of the pulse oximetry value of the current study consistent with those of randomized trials [2, 9]. NIV improves oxygenation similar to invasive ventilation [2]. While, HCO has a positive end-expiratory pressure effect to improve oxygenation [19], which has a lower intensity than NIV [5, 6]. Also, $\mathrm{HCO}$ could be generated $1-3 \mathrm{~cm} \mathrm{H}_{2} \mathrm{O}$ a positive end-expiratory pressure to improve oxygenation, that is lower than that generated by NIV [20]. Laryngeal/ esophageal illness/ injuries that led to allocation to HCO. The injuries to these structures confound the results (e.g., the effects that damage to these structures may have action on preoxygenation, laryngoscopy and intubation). The effect of apneic oxygenation during laryngoscopy by NIV is superior to that does by HCO but further research is required to compare NIV with $\mathrm{HCO}$ without bias of the inclusion criteria to state the hypothesis clearly.

They study involved a large sample size and can provide important information for management of patients with acute respiratory failure. Still, there are defects in the study, for example, a non-randomized retrospective study, and lack of a control group of preoxygenation with the Bag Valve Mask. The mortality was not the primary outcome of the study but available randomized controlled trials $[9-12,21]$ have assessed mortality as

Table 4 The parameters for laryngoscopy

\begin{tabular}{lll}
\hline Parameters & Cohorts & HCO \\
\cline { 2 - 3 } $\begin{array}{l}\text { PrV } \\
\text { Procedure for oxygenation and ventilation }\end{array}$ & Non-invasive ventilation & High-flow nasal cannula oxygen \\
Patients included in the analysis & $\mathbf{1 5 4}$ & $\mathbf{1 6 1}$ \\
\hline Time duration of laryngoscopy (min) & & $96(59)$ \\
$<1$ & $87(56)$ & $51(32)$ \\
$1-3$ & $52(34)$ & $14(9)$ \\
$>3$ & $15(10)$ & 0.847 \\
Number of laryngoscopies attempts & & $126(78)$ \\
1 & $123(80)$ & $28(18)$ \\
\hline 3 or procedural time $\geq 10$ min & $23(15)$ & $7(4)$ \\
\hline
\end{tabular}

Variables are reported as frequency (percentages)

The Fischer exact test was performed for statistical analysis

A $p$-value of less than 0.05 was considered significant 
Table 5 Intubation scoring items

\begin{tabular}{|c|c|c|c|}
\hline \multirow{3}{*}{$\begin{array}{l}\text { Scoring items } \\
\text { Procedure for oxygenation and ventilation }\end{array}$} & \multicolumn{2}{|l|}{ Cohorts } & \multirow{3}{*}{$\begin{array}{l}\text { Comparisons } \\
\text { between } \\
\text { cohorts }\end{array}$} \\
\hline & NIV & $\mathrm{HCO}$ & \\
\hline & Non-invasive ventilation & High-flow nasal cannula oxygen & \\
\hline Patients included in the analysis & 154 & 161 & $p$-value \\
\hline \multicolumn{4}{|l|}{ MACOCHA score } \\
\hline$<3$ & $123(80)$ & $134(83)$ & 0.469 \\
\hline$\geq 3$ & $31(20)$ & $27(17)$ & \\
\hline \multicolumn{4}{|l|}{ Modified Cormack-Lehane grade } \\
\hline I, IIA, or IIB & $139(90)$ & $144(89)$ & 0.854 \\
\hline III or IV & $15(10)$ & $17(11)$ & \\
\hline \multicolumn{4}{|l|}{ Intubation Difficulty Scale score } \\
\hline $0-2$ & $15(10)$ & $14(9)$ & 0.733 \\
\hline $3-4$ & $87(57)$ & $98(61)$ & \\
\hline$\geq 5$ & $52(34)$ & $49(30)$ & \\
\hline
\end{tabular}

Variables are reported as frequency (percentages)

The Mann-Whitney $U$-test was performed for statistical analysis

A $p$-value of less than 0.05 was considered significant

the primary outcome. Also, mortality is a major outcome in studies for critically ill patients [22]. The treatment effects were not considered on the results. Patients who had a Glasgow coma score $<8 \quad(n=6)$ were excluded from the analysis. However, data of these patients are unlikely to affect results of the current study. The study was evaluated MACOCHA score in addition to Intubation Difficulty Scale score. The Intubation Difficulty Scale score is used a posteriori and not a priori [23]. Therefore, the study was evaluated MACOCHA score in addition to Intubation Difficulty Scale score. A total of minimum 10 min were chosen to insert the endotracheal tube using conventional laryngoscopy. This arbitrary time frame would not align with best practice nor current evidence. The non-trained physicians were also involved in the study. Therefore, $10 \mathrm{~min}$ was required to insert the endotracheal tube into the trachea. Most patients with acute respiratory failure are intubated in emergency department or general ward; it is rare that an acute respiratory failure patient is intubated in the

Table 6 The immediate complications during intubation procedure

\begin{tabular}{|c|c|c|c|}
\hline \multirow[t]{2}{*}{ Complications } & \multicolumn{2}{|l|}{ Cohorts } & \multirow{2}{*}{$\begin{array}{l}\text { Comparisons } \\
\text { between } \\
\text { cohorts }\end{array}$} \\
\hline & NIV & $\mathrm{HCO}$ & \\
\hline Procedure for oxygenation and ventilation & Non-invasive ventilation & High-flow nasal cannula oxygen & \\
\hline Patients included in the analysis & 154 & 161 & $p$-value \\
\hline Use of alternative management devices & $17(11)$ & $23(14)$ & 0.403 \\
\hline Agitation & $2(1)$ & $1(1)$ & 0.616 \\
\hline At least one episode of systolic arterial hypotension $<90 \mathrm{mmHg}$ & $71(46)$ & $83(52)$ & 0.368 \\
\hline Bradycardia & $3(2)$ & $5(3)$ & 0.724 \\
\hline Sustained arrhythmia & $4(3)$ & $3(2)$ & 0.718 \\
\hline Esophageal intubation & $9(6)$ & $8(5)$ & 0.806 \\
\hline Regurgitation & $1(1)$ & $2(1)$ & 0.998 \\
\hline Gastric distension & $12(8)$ & $11(7)$ & 0.829 \\
\hline Injuries in the oral cavity & $1(1)$ & $2(1)$ & 0.998 \\
\hline New infiltrate on chest radiograph & $29(19)$ & $33(20)$ & 0.777 \\
\hline Cardiac arrest & $2(1)$ & $8(5)$ & 0.105 \\
\hline
\end{tabular}

Variables are reported as frequency (percentages)

The Fischer exact test was performed for statistical analysis

A $p$-value of less than 0.05 was considered significant 
Table 7 The late occurring complications during intubation procedure

\begin{tabular}{|c|c|c|c|}
\hline \multirow[t]{2}{*}{ Complications } & \multicolumn{2}{|l|}{ Cohorts } & \multirow{3}{*}{$\begin{array}{l}\text { Comparisons } \\
\text { between } \\
\text { cohorts }\end{array}$} \\
\hline & NIV & $\mathrm{HCO}$ & \\
\hline Procedure for oxygenation and ventilation & Non-invasive ventilation & High-flow nasal cannula oxygen & \\
\hline Patients included in the analysis & 154 & 161 & $p$-value \\
\hline Sepsis-related Organ Failure Assessment score at 1 & $9.89 \pm 2.52$ & $10.45 \pm 3.52$ & 0.107 \\
\hline Sepsis-related Organ Failure Assessment score at 7 & $6.12 \pm 1.22$ & $6.62 \pm 3.15$ & 0.066 \\
\hline Ventilator-associated pneumonia & $38(25)$ & $32(20)$ & 0.344 \\
\hline Duration of mechanical ventilation (days) & $11.12 \pm 3.45$ & $11.78 \pm 3.11$ & 0.075 \\
\hline Length of stay in the intensive care unit (days) & $14.11 \pm 3.16$ & $14.22 \pm 4.12$ & 0.791 \\
\hline Death within a month & $43(28)$ & $51(32)$ & 0.538 \\
\hline
\end{tabular}

Constant variables are reported as frequency (percentages) and continuous and ordinal data are demonstrated as mean \pm standard deviation (SD)

The Fischer exact test was performed for constant data and the Mann-Whitney $U$-test was performed for continuous and ordinal data

A $p$-value of less than 0.05 was considered significant

intensive care unit. Before transferring to the intensive care unit, the acute respiratory failure should be corrected, otherwise, there is high risk of cardiac arrest during transportation. The possible justification for the same is that the current study had included patients those were admitted in the intensive care unit and underwent emergency intubation due to the acute respiratory failure.

\section{Conclusions}

When compared, there was no difference between noninvasive ventilation technique and high-flow oxygen therapy to minimize severe hypoxia prior to laryngoscopy and endotracheal intubation in patients with acute respiratory failure. However, the effect of apneic oxygenation during laryngoscopy by non-invasive ventilation is superior to that does by high-flow oxygen therapy especially for patients with moderate-to-severe hypoxemia before preoxygenation.

\section{Abbreviations}

HCO: High-flow nasal cannula oxygen therapy (high-flow oxygen); MACOCHA score: Mallampati score III or IV, apnea syndrome, cervical spine limitation, opening mouth $<3 \mathrm{~cm}$, coma, hypoxia, and non-trained anesthesiologists score; NIV: Non-invasive ventilation; SD: Standard deviation; SOFA: Sepsis-related Organ Failure Assessment

\section{Acknowledgments}

Authors are thankful for the medical staff and non-medical staff of the Chinese PLA General Hospital, Beijing, China.

\section{Authors' contributions}

Both authors have read and approved the manuscript for publication. CZ was project administrator, contributed to supervision, the literature review, investigation, formal analysis, and methodology of the study. MO contributed to methodology, literature review, conceptualization, data curation of the study, draft and edited the manuscript for intellectual content. Both authors agree to be accountable for all aspects of work ensuring integrity and accuracy.

\section{Funding}

None.
Availability of data and materials

The datasets were used and analyzed during the current study available from the corresponding author on reasonable request.

Ethics approval and consent to participate

The designed protocol (PLA151720 dated August 6, 2020) was approved by the human ethics committee of the Chinese PLA General Hospital and the Chinese society of critical care medicine. An informed consent form was signed by patients and relatives (legally authorized person) of the enrolled patients regarding anesthesia and intubation (if required) before admission to the hospital. The study reporting adheres to the law of China and the V2008 Declarations of Helsinki.

Consent for publication

None.

\section{Competing interests}

The authors declared that they have no conflict of interest or any other competing interest regarding results and/ or discussion reported in the research.

Received: 19 September 2020 Accepted: 4 January 2021

Published online: 14 January 2021

\section{References}

1. Roux D, Reignier J, Thiery G, Boyer A, Hayon J, Souweine B, Papazian L, Mercat A, Bernardin G, Combes A, Chiche JD, Diehl JL, du Cheyron D, L'her E, Perrotin D, Schneider F, Thuong M, Wolff M, Zeni F, Dreyfuss D, Ricard JD. Acquiring procedural skills in ICUs: a prospective multicenter study. Crit Care Med. 2014;42:886-95.

2. Frat JP, Ricard JD, Quenot JP, Pichon N, Demoule A, Forel JM, Mira JP, Coudroy R, Berquier G, Voisin B, Colin G, Pons B, Danin PE, Devaquet J, Prat G, Clere-Jehl R, Petitpas F, Vivier E, Razazi K, Nay MA, Souday V, Dellamonica J, Argaud L, Ehrmann S, Gibelin A, Girault C, Andreu P, Vignon P, Dangers L, Ragot S, Thille AW, FLORALI-2 study group; REVA network. Non-invasive ventilation versus high-flow nasal cannula oxygen therapy with apnoeic oxygenation for preoxygenation before intubation of patients with acute hypoxaemic respiratory failure: a randomised, multicentre, open-label trial. Lancet Respir Med. 2019;7:303-12.

3. Jaber S, Jung B, Corne P, Sebbane M, Muller L, Chanques G, Verzilli D, Jonquet O, Eledjam JJ, Lefrant JY. An intervention to decrease complications related to endotracheal intubation in the intensive care unit: a prospective, multiple-center study. Intensive Care Med. 2010;36:248-55.

4. De Jong A, Rolle A, Molinari N, Paugam-Burtz C, Constantin JM, Lefrant JY, Asehnoune K, Jung B, Futier E, Chanques G, Azoulay E, Jaber S. Cardiac arrest and mortality related to intubation procedure in critically ill adult patients: a multicenter cohort study. Crit Care Med. 2018;46:532-9.

5. Frat JP, Brugiere B, Ragot S, Chatellier D, Veinstein A, Goudet V, Coudroy R, Petitpas F, Robert R, Thille AW, Girault C. Sequential application of oxygen 
therapy via high-flow nasal cannula and noninvasive ventilation in acute respiratory failure: an observational pilot study. Respir Care. 2015;60:170-8.

6. Frat JP, Thille AW, Mercat A, Girault C, Ragot S, Perbet S, Prat G, Boulain T, Morawiec E, Cottereau A, Devaquet J, Nseir S, Razazi K, Mira JP, Argaud L, Chakarian JC, Ricard JD, Wittebole X, Chevalier S, Herbland A, Fartoukh M, Constantin JM, Tonnelier JM, Pierrot M, Mathonnet A, Beduneau G, Deletage-Métreau C, Richard JC, Brochard L, Robert R, FLORALI Study Group; REVA Network. High-flow oxygen through nasal cannula in acute hypoxemic respiratory failure. N Engl J Med. 2015;372:2185-96.

7. Arino Irujo JJ, Velasco JM, Moral P, Carrillo B, Lopez-Timoneda F. Delivered oxygen fraction during simulated cardiopulmonary resuscitation depending on the kind of resuscitation bag and oxygen flow. Eur J Emerg Med. 2012; 19:359-62.

8. Miguel-Montanes R, Hajage D, Messika J, Bertrand F, Gaudry S, Rafat C, Labbé V, Dufour N, Jean-Baptiste S, Bedet A, Dreyfuss D, Ricard JD. Use of high-flow nasal cannula oxygen therapy to prevent desaturation during tracheal intubation of intensive care patients with mild-to-moderate hypoxemia. Crit Care Med. 2015;43:574-83.

9. Baillard C, Prat G, Jung B, Futier E, Lefrant JY, Vincent F, Hamdi A, Vicaut E, Jaber $\mathrm{S}$. Effect of preoxygenation using non-invasive ventilation before intubation on subsequent organ failures in hypoxaemic patients: a randomised clinical trial. Br J Anaesth. 2018;120:361-7.

10. Semler MW, Janz DR, Lentz RJ, Matthews DT, Norman BC, Assad TR, Keriwala RD, Ferrell BA, Noto MJ, McKown AC, Kocurek EG, Warren MA, Huerta LE, Rice TW, Investigators FELLOW, Pragmatic Critical Care Research Group. Randomized trial of apneic oxygenation during endotracheal intubation of the critically ill. Am J Respir Crit Care Med. 2016;193:273-80.

11. Simon M, Wachs C, Braune S, de Heer G, Frings D, Kluge S. High-flow nasal cannula versus bag-valve-mask for preoxygenation before intubation in subjects with hypoxemic respiratory failure. Respir Care. 2016;61:1160-7.

12. Vourc'h M, Asfar P, Volteau C, Bachoumas K, Clavieras N, Egreteau PY, Asehnoune K, Mercat A, Reignier J, Jaber S, Prat G, Roquilly A, Brule N, Villers D, Bretonniere C, Guitton C. High-flow nasal cannula oxygen during endotracheal intubation in hypoxemic patients: a randomized controlled clinical trial. Intensive Care Med. 2015;41:1538-48.

13. Yu Z, Zhou N, Li A, Chen J, Chen H, He Z, Yan F, Zhao H, Zhu J. Performance assessment of the SAPS II and SOFA scoring systems in hanta virus hemorrhagic fever with renal syndrome. Int J Infect Dis. 2017;63:88-94.

14. Schmid K, Buehler PK, Schmitz A, Both CP, Weiss M. Frequency distribution of modified Cormack-Lehane views-a retrospective audit of tracheal intubation in children with normal airways. Acta Anaesthesiol Scand. 2019; 63:1001-8.

15. Nasa VK, Kamath SS. Risk factors assessment of the difficult intubation using intubation difficulty scale (IDS). J Clin Diagn Res. 2014;8:GC01-3.

16. De Jong A, Molinari N, Terzi N, Mongardon N, Arnal JM, Guitton C, Allaouchiche B, Paugam-Burtz C, Constantin JM, Lefrant JY, Leone M, Papazian L, Asehnoune K, Maziers N, Azoulay E, Pradel G, Jung B, Jaber S, AzuRea Network for the Frida-Rea Study Group. Early identification of patients at risk for difficult intubation in the intensive care unit: development and validation of the MACOCHA score in a multicenter cohort study. Am J Respir Crit Care Med. 2013;187:832-9.

17. Joseph A, Zafrani L, Mabrouki A, Azoulay E, Darmon M. Acute kidney injury in patients with SARS-CoV-2 infection. Ann Intensive Care. 2020;10:117.

18. ARDS Definition Task Force, Ranieri VM, Rubenfeld GD, Thompson BT, Ferguson ND, Caldwell E, Fan E, Camporota L, Slutsky AS. Acute respiratory distress syndrome: the Berlin Definition. JAMA. 2012;307:2526-33.

19. Mauri T, Turrini C, Eronia N, Grasselli G, Volta CA, Bellani G, Pesenti A Physiologic effects of high-flow nasal cannula in acute hypoxemic respiratory failure. Am J Respir Crit Care Med. 2017;195:1207-15.

20. Parke RL, Eccleston ML, McGuinness SP. The effects of flow on airway pressure during nasal high-flow oxygen therapy. Respir Care. 2011;56:1151-5.

21. Jaber S, Monnin M, Girard M, Conseil M, Cisse M, Carr J, Mahul M, Delay JM, Belafia F, Chanques G, Molinari N, De Jong A. Apnoeic oxygenation via high-flow nasal cannula oxygen combined with non-invasive ventilation preoxygenation for intubation in hypoxaemic patients in the intensive care unit: the single-Centre, blinded, randomised controlled OPTINIV trial. Intensive Care Med. 2016;42:1877-87.
22. Gaudry S, Messika J, Ricard JD, Guillo S, Pasquet B, Dubief E, Boukertouta T, Dreyfuss D, Tubach F. Patient-important outcomes in randomized controlled trials in critically ill patients: A systematic review. Ann Intensive Care. 2017;7:28.

23. De Jong A, Jung B, Jaber S. Intubation in the ICU: we could improve our practice. Crit Care. 2014;18:209.

\section{Publisher's Note}

Springer Nature remains neutral with regard to jurisdictional claims in published maps and institutional affiliations.
Ready to submit your research? Choose BMC and benefit from:

- fast, convenient online submission

- thorough peer review by experienced researchers in your field

- rapid publication on acceptance

- support for research data, including large and complex data types

- gold Open Access which fosters wider collaboration and increased citations

- maximum visibility for your research: over $100 \mathrm{M}$ website views per year

At BMC, research is always in progress.

Learn more biomedcentral.com/submissions 